\title{
Research on Reliability of Relaying Protection in Smart Substation
}

\author{
Kai Wang, Wanqing Li \\ Department of Electrical Engineering and Automation, College of Electrical Engineering \& New Energy, China Three Gorges \\ University, Yichang, China \\ Email: Kyriek1998@gmail.com
}

How to cite this paper: Wang, K. and Li, W.Q. (2019) Research on Reliability of Relaying Protection in Smart Substation. World Journal of Engineering and Technology, 7, 333-338.

https://doi.org/10.4236/wjet.2019.72024

Received: April 22, 2019

Accepted: May 14, 2019

Published: May 17, 2019

Copyright (c) 2019 by author(s) and Scientific Research Publishing Inc. This work is licensed under the Creative Commons Attribution International License (CC BY 4.0).

http://creativecommons.org/licenses/by/4.0/

(c) (i) Open Access

\begin{abstract}
Research on reliability of relaying protection in smart substation not only has a positive effect on the rational configuration scheme of relaying protection in smart substation, but also can promote the stability and safety of the overall operation of power system. There are many reliability strategies for relaying protection in smart substation. In practice, the key points of relaying protection should be clarified. Based on the reality, the protection configuration should be strengthened; the voltage limited delay should be used for protection, and the protection configuration scheme of actual lines should be paid attention to, so as to improve the reliability of relaying protection in smart substation and promote the realization of stable and sustainable development of power system and smart substation.
\end{abstract}

\section{Keywords}

Smart Substation, Relaying Protection, Reliability

\section{The Concept of Smart Substation}

Establishing an information management system in smart substation can effectively improve the function of collecting information, transmitting information, and processing information in smart substation. Smart substation uses a large number of network technologies. Digital technology provides guarantee for the smoothness of network information. Under the premise of ensuring the intelligentization of equipment, the advantages of network information application are given full play to unify the control of the distribution device in the substation system. Primary intelligence and secondary network are the most significant characteristics of smart substation. This application mode reduces the operating cost of substation to a large extent and improves the working efficiency of subs- 
tation. In the process of applying smart substation, the mutual inductor problem in the traditional substation is solved by using the intelligent management. The application of smart substation has changed the way of using optical cable, and solved the problems of electromagnetic compatibility in traditional substation, such as AC and DC crosstalk. The application of relaying protection device improves the substation environment and enhances the stability of the power system [1]. The station control layer, the interval layer and the process layer are the three general parts of the smart substation structure. The station control layer and the interval layer can realize the data sharing while controlling the power data, and optimize the information management function of the substation. The role of the layer in smart substation is a transitional effect, ensuring the stability of the substation during use. The role of the relaying protection device is to maintain the stability of the smart substation to ensure the safe operation of its internal electric power unit. Table 1 is the comparison between smart grid and traditional power grid.

\section{Key Points of Relaying Protection}

\subsection{Real-Time Capabilities}

The relaying protection of smart substation faces very high real-time requirements in the power system, because the digital transformer is working on digital sampling, it will be affected by the switch, for example, the reception time of the receiver is prolonged, link propagation of the combiner occurs and other factors affect the data transmission [2]. In this process, combiner queuing and switch forwarding are one of the key factors for the time error of the digital transformer. Therefore, it is necessary for relevant operators to develop a scientific and reasonable sampling scheme. Before that, the possible errors should be calculated and then the sampling work should be carried out. The results of calculation and sampling should be organically combined to minimize errors and delays, which is conducive to the improvement of real-time performance of relay protection in smart substation.

Table 1. The comparison between smart grid and traditional power grid.

\begin{tabular}{lll}
\hline $\begin{array}{l}\text { Characteristic } \\
\text { Whether to encourage } \\
\text { users to participate in }\end{array}$ & $\begin{array}{l}\text { The user does not know and } \\
\text { does not participate in }\end{array}$ & Smart grid \\
$\begin{array}{l}\text { Whether to accommodate } \\
\text { power generation and } \\
\text { energy storage }\end{array}$ & $\begin{array}{l}\text { generation, distributed power } \\
\text { supply is restricted }\end{array}$ & $\begin{array}{l}\text { Large amount of renewable distributed } \\
\text { power supply is convenient_ "plug and }\end{array}$ \\
$\begin{array}{l}\text { Whether to meet the } \\
\text { power quality } \\
\text { requirements }\end{array}$ & $\begin{array}{l}\text { Concerned about outages, not } \\
\text { concerned with power quality }\end{array}$ & $\begin{array}{l}\text { Power quality first, there are a variety of } \\
\text { power quality options and price options }\end{array}$ \\
$\begin{array}{l}\text { Whether to optimize } \\
\text { assets and operate } \\
\text { efficiently }\end{array}$ & $\begin{array}{l}\text { Operational data and asset } \\
\text { management are rarely } \\
\text { integrated }\end{array}$ & $\begin{array}{l}\text { Expand the collection of power grid } \\
\text { parameters, focus on accident } \\
\text { prevention, reduce the impact on users, } \\
\text { optimize the allocation of resources, }\end{array}$ \\
\end{tabular}




\subsection{Synchronization}

There is no problem of time synchronization in the transformer equipment used in the traditional substation, so the protection of the power system in this aspect is relatively deficient; the smart substation uses the digital method for information collection, so its power distribution protection should be synchronously connected with the time. The synchronization and reliability of relay protection of smart substation can be guaranteed by the following methods: the first is the detection and the practice of line differential protection during this period, because at the same time detection device and circuit differential protection device need to collect the amplitude and phase signal from two different substation. In addition to the data on the side of the line, it also involves certain contralateral data. Therefore, it is necessary to ensure that the power system is correctly and synchronously protected. The second is the implementation of overvoltage and overcurrent protection, overvoltage and overcurrent protection is very simple, do not need to maintain a completely synchronous time. Only relevant operators need to input the correct amplitude into the relaying protection system of the smart substation [3].

\section{Methods to Improve the Reliability of Relaying Protection System in Smart Substation}

\subsection{Reliability Improvement of Transformer}

The power system has high requirements for the voltage limit. Therefore, only the accuracy of the voltage limit is guaranteed, and the power supply and distribution of the power system can be operated normally [4]. In the practical process of realizing effective control voltage, the most decisive role is the application of the transformer system. Therefore, improving the reliability protection of the transformer plays a vital role in the normal stability of the power system. It is so important in transformer protection system reliability of smart substation relaying protection system based on reliability, in the process of configuration of transformer substation, the transformer can be configured in a distributed way, which can disperse the system pressure of transformer to a certain extent, so as to avoid problems of transformer caused by excessive pressure, in the late configuration of the smart substation relay protection system, it is necessary to combine centralized configuration with decentralized configuration, so as to reduce the system complexity and achieve the function of transformer protection smart substation relaying protection system and improve the reliability of smart substation relay protection system.

\subsection{Relaying Protection of Process Layer}

The relaying protection of the smart substation through the process layer is mainly to protect the transformers, distribution lines and busbars in the power system. By protecting these configurations, the operation risk of the power system can be reduced, and the necessary protection measures can be implemented 
for the power dispatching system, so as to ensure the normal operation of the power system. In general, the stability of the electromechanical protection system of the smart substation can maintain the stability of fixed value to a certain extent when the power system fluctuates, so as to ensure the normal and stable operation of the power system of the substation. However, there are a large number of disposable equipment applications in smart substations. In this process, the separation of hardware and switches should be emphasized and the relative independence of hardware and switches should be guaranteed, so as to protect the transmission lines and busbars of smart substation. In the process of relaying protection of actual smart substation, the protection of transformer and busbars of smart substation can be redefined by protecting multi-segment lines. While sampling at the main station of the smart substation, the sampling data should be adjusted in real time to ensure the reliability and applicability of the data sampling results.

\subsection{Improvement on the Relaying Protection of Interval Layer}

The application of dual device in the relaying protection system of smart substation can realize the centralized configuration of backup protection, which is a very effective measure to improve the relaying protection of interval layer and the system reliability. The backup protection system can provide effective protection for the switch, backup equipment and adjacent terminal busbars and lines of the smart substation; It can accurately judge various problems and faults in the operation of the power system and provide timely, correct and effective solutions to the problems. In addition, within the controllable range of technical means, the intelligent substation voltage level can be centrally configured to enable it adapt to the actual operation of the power grid. At the same time, after the actual analysis of the actual situation of the power grid system, several sets of scientific and reasonable substation operation schemes can be designed, and the most practical and effective schemes are selected according to the analysis of actual situation, and the role of the interval layer in the relaying protection of smart substation can be played to the extreme.

\subsection{Reliability Improvement of Ring Busbar}

The ring structure itself is a very reliable structure. Therefore, the ring structure itself is a very reliable structure. Therefore, the use of ring structure in the protection configuration of the busbar plays a very important and critical role in the reliability of the electromechanical protection system of the smart substation. So we must do a good job in the ring structure of the relaying protection system of the smart substation, and further enhance the reliability of the ring busbar protection [5]. By collecting and analyzing the minimum node of electric circuit, it can be concluded that the protection reliability of the traditional structural busbar is very low, and the protection reliability of the ring busbar can meet the reliability requirements in electromechanical protection system of smart substa- 
tion, Moreover, the damage of the ring structure to the components is much smaller than that of the traditional structure, which can promote the improvement of the reliability and safety of the relaying protection system of smart substation. Therefore, the busbar protection configuration in the electromechanical protection system of smart substation is integrated into the ring structure, which can improve the reliability of its relaying protection system.

\subsection{Optimizing Line Protection Configuration and Carrying out Reasonable Inspections}

The specific measures are as follows: 1) When optimizing the line protection and configuration work, the operators can use the back type and the centralized type. And the operators can monitor through the communication system, the voltage interval unit protection, this can be found in a timely manner all kinds of problems in the system and take effective measures to solve it, so as to improve the smart grid system in the process of running reliability and safety. 2) In the rapid development of modern science and technology, intelligent is also in constant development, so the demand in human resources gradually become smaller, but human resources are still indispensable conditions in the operation of the voltage system. In the improvement of the reliability of the relaying protection system of smart substation, the inspection of the system should be emphasized; a professional inspection team with professional qualities and skills can be set up. Meanwhile, a perfect inspection measure and system can be formulated to implement the inspection work and clearly indicate the work scope and responsibilities of the inspection staff.

\section{Conclusion}

The relaying protection system of smart substation can detect and solve the fault problems in time when the power system is in trouble, which is a key part to ensure the normal operation of the power system. On this basis, the author explores the reliability of relaying protection system in smart substation and analyzes the improvement method of reliability. The purpose is to make the relaying protection system in smart substation more secure and stable, and to provide guarantee for the stable operation of the substation power system.

\section{Conflicts of Interest}

The authors declare no conflicts of interest regarding the publication of this paper.

\section{References}

[1] Huang, Y.X. (2017) Reliability Analysis of Relaying Protection System in Smart Substation. Telecom World, No.8, 177-178.

[2] Zhao, L.P. (2017) A Method for Improving Reliability of Relaying Protection System in Smart Substation. Science and Technology Innovation, No. 35, 68-69.

[3] Tao, W.L., Tang, X.P., Tang, X.P., et al. (2018) Research on Hidden Fault Diagnosis 
Method for Relaying Protection in Smart Substation Based on Multi-Dimensional Mixing Quantity. Electrical Engineering, No. 3, 1-4.

[4] Ren, H.M. and Sun, D. (2018) Reliability Evaluation of Relaying Protection Device Based on Smart Substation. China Science and Technology, 591, 75-76.

[5] Ye, B.S., Qiu, X.G. and Liu, Y.Q. (2017) A Method for Improving Reliability of Relaying Protection System in Smart Substation. Electronic Technology and Software Engineering, 23, 235-235. 